\title{
USO E OCUPAÇÃO DAS ÁREAS DE PRESERVAÇÃO PERMANENTE DA BACIA HIDROGRÁFICA DO CÓRREGO DO LIMÃO, PASSOS-MG
}

\author{
Leticia de Paulo Donato ${ }^{1}$, Rômulo Amaral Faustino Magri² \\ ${ }^{1}$ Engenheira Ambiental pela Universidade do Estado de Minas Gerais - Unidade \\ Passos \\ ${ }^{2}$ Mestre em Geotecnia (USP), Doutorando em Engenharia Hidráulica e Saneamento \\ (USP), Professor do Curso de Engenharia Ambiental da Universidade do Estado de \\ Minas Gerais - Unidade Passos. (romulo.magri@uemg.br) \\ Recebido em: 08/04/2017 - Aprovado em: 10/06/2017 - Publicado em: 20/06/2017 \\ DOI: 10.18677/EnciBio_2017A101
}

\begin{abstract}
RESUMO
Com a urbanização acelerada e sem planejamento, as bacias hidrográficas vêm sofrendo sérios problemas ambientais devido ao inadequado uso e ocupação do solo. As matas ciliares que são encontradas as margens de rios e nascentes, tem o papel não só de proteger os corpos d'água, mas também atua como barreira contra processos erosivos. E mesmo assim são removidas, prejudicando a estabilização natural do ecossistema, os processos erosivos ocorrem, alterando a qualidade da agua, dentre outros problemas. Sendo assim, este trabalho visou analisar o uso e ocupação das Áreas de Preservação Permanente - APP da bacia do córrego do Limão, situado no município de Passos/MG, visando identificar os usos inadequados, as degradações e propor medidas de recuperação. Para isso, foram feitas visitas em campo, e trabalhos realizados em laboratório de geoprocessamento para obter os dados sobre os usos e ocupações da bacia e sobre a degradação da APP da bacia. O mapa de uso e ocupação evidenciou que trata-se de uma bacia urbanizada, visto que mais de $40 \%$ de sua área total é ocupada por esta classe. Em relação às áreas de preservação permanente, $48 \%$ de sua área total é abrangida por vegetação arbórea fechada. Contudo, foram identificadas degradações ambientais como disposição irregular de resíduos sólidos, processos erosivos e desmatamento.
\end{abstract}

PALAVRAS-CHAVE: Degradação ambiental, geoprocessamento, mata ciliar.

\section{ANALYSIS OF THE LAND USE IN AREAS OF PERMANENT PRESERVATION OF THE WATERSHED OF THE LIMÃO STREAM, PASSOS-MG}

\begin{abstract}
With urbanization accelerated and unplanned, river basins have been suffering serious environmental problems due to inadequate land use. The riparian forests that are found along the banks of rivers and springs have the role not only of protecting water bodies, but also act as a barrier against erosive processes. And yet they are removed, damaging the natural stabilization of the ecosystem, erosive processes occur, altering the quality of water, among other problems. Therefore, this study aimed to analyze the use and occupation of the Permanent Preservation Areas PPA of the stream basin of Limão, located in the city of Passos/MG, aiming to identify the inadequate uses, their degree of degradation and propose recovery ENCICLOPÉDIA BIOSFERA, Centro Científico Conhecer - Goiânia, v.14 n.25; p.78 2017
\end{abstract}


measures. Field visits were made, and work was done in a geoprocessing laboratory to obtain data on basin uses and occupations and on a degradation of basin APP. Field visits were made, and work was done in a geoprocessing laboratory to obtain data on basin land uses and on a degradation of PPA basin. The map of land use showed that it is an urbanization, since more than $40 \%$ of its total area is occupied by this class. In relation to permanent conservation areas, $48 \%$ of its total area is covered by closed tree vegetation. However, environmental degradation was identified as irregular solid waste, erosion processes and deforestation.

KEYWORDS: riparian forest, environmental degradation, geoprocessing.

\section{INTRODUÇÃO}

O crescimento desordenado da cidade e da população vem trazendo sérios problemas ambientais em bacias hidrográficas devido ao inadequado uso e ocupação do solo, principalmente nas Áreas de Preservação Permanente (APP), que são áreas protegidas por leis específicas. A retirada da vegetação nativa para abertura de estradas, loteamentos, são exemplos de ações antrópicas que buscam uma melhora na qualidade de vida, que por outro lado, é uma ameaça ao futuro em relação à natureza (JACOB, 2010).

Com a urbanização acelerada, áreas não destinadas a esta finalidade vêm sendo ocupadas, até mesmo as APPs, que, segundo o Código Florestal Federal são áreas protegidas, cobertas ou não por vegetação nativa, com a função ambiental de preservar os recursos hídricos, a paisagem, a estabilidade geológica e a biodiversidade, facilitar o fluxo gênico de fauna e flora, proteger o solo e assegurar o bem-estar das populações humanas (BRASIL, 2012). A ocupação irregular das APPs em bacias hidrográficas urbanas acontece na maioria dos municípios brasileiros, resultando em dispendiosos gastos aos cofres públicos, relativos ao gerenciamento e recuperação das áreas degradadas pelas atividades antrópicas desordenadas (LIMA \& CHAVES, 2013).

São diversos os problemas ambientais causados pelo desmatamento e ocupação irregular de matas ciliares dos canais fluviais urbanos, podendo ser citados: maus cheiros, doenças, problemas de abastecimento de água potável e água para uso, erosões, enchentes, problemas no tráfego fluvial e diversos outros, que sabidamente causaram muitos prejuízos econômicos e na qualidade de vida das pessoas (SILVA NETO et al., 2013).

Embora existam leis específicas em prol do meio ambiente, com essa aceleração da urbanização causada pelo homem sem nenhum tipo de planejamento, quem está sofrendo consequências diretas são as APPs, que não são respeitadas e estão sendo ocupadas de modo irregular e degradante (GARCIA et al., 2015). Neste contexto, o presente trabalho objetiva analisar o uso e ocupação dos solos nas Áreas de Preservação Permanente (APPs) de recursos hídricos na bacia hidrográfica do córrego do Limão, município de Passos-MG, visando identificar os conflitos de uso, as degradações e indicar propostas de recuperação.

\section{Caracterização da Área de Estudo}

\section{MATERIAL E MÉTODOS}

A microbacia hidrográfica do córrego do Limão está localizada em PassosMG, na Mesorregião do Sul e Sudoeste de Minas Gerais. A microbacia em estudo está inserida na bacia do Ribeirão Bocaina, que por sua vez deságua na bacia do médio Rio Grande (Figura 1). 
Compõem a geologia da área de estudo rochas do embasamento cristalino: xisto, quartzito e gnaisse (COLLARES, 2013). O relevo é caracterizado por colinas com baixas declividades e amplitude altimétrica de até 100m (MAGRI et al., 2013). Quanto aos solos, predominam latossolos vermelhos e vermelhos amarelos e há ocorrência de argissolos vermelhos amarelos (ANDRADE \& FONSECA, 2013).

O município de Passos possui uma população de 113.807 habitantes, distribuídos em uma área total de $1.339 \mathrm{~km}^{2}$. Situa-se a 745 metros acima do nível do mar e possui clima Tropical de Altitude, com temperatura média anual superior a $18^{\circ} \mathrm{C}$ e inverno seco. A precipitação média anual é de 1.709,4 mm (IBGE, 2017).
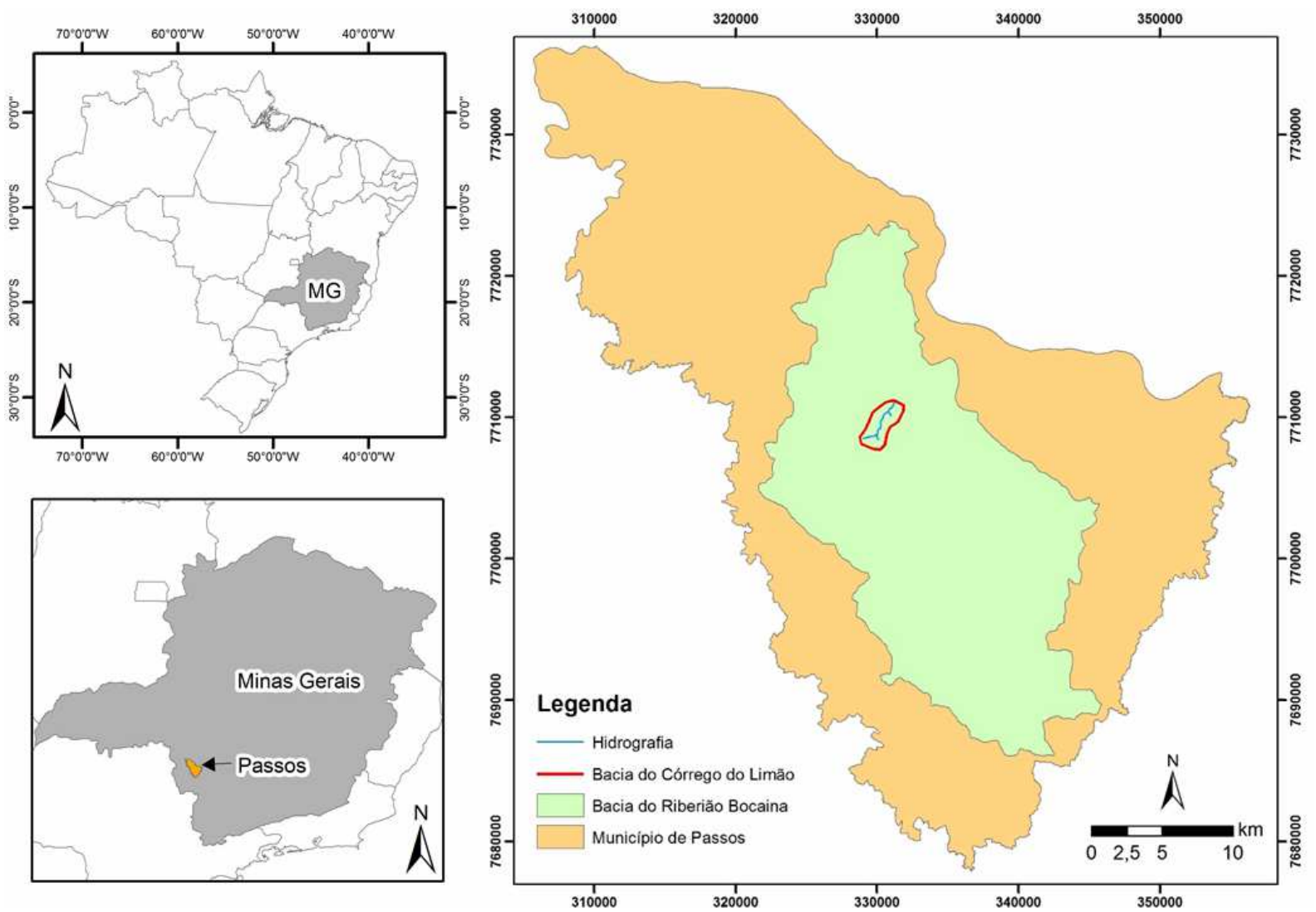

FIGURA 1. Localização da bacia do Córrego do Limão no estado, no município e na bacia do Ribeirão Bocaina. Fonte: Os Autores

\section{Aspectos Metodológicos}

A sistemática de trabalho envolveu atividades em campo e em laboratório de geoprocessamento, que foram realizadas de forma intercalada. Incialmente foi preparada uma base cartográfica que possibilitou o planejamento e execução de análises e levantamentos de campo.

Para composição da base cartográfica utilizou-se a carta topográfica de Passos em escala 1:50.000, disponibilizada pelo IBGE, sendo o seu datum o Córrego Alegre. A carta foi georreferenciada no programa ArcGIS ${ }^{\circledR}$ e convertida para o datum SIRGAS 2000. Após o georreferenciamento da carta, criou-se shapefiles específicos para cada layer (hidrografia, área de estudo, nascente, ponto cotado, etc.) e vetorizou-se as informações contidas na carta topográfica.

A delimitação da bacia hidrográfica foi feita manualmente por meio da análise do relevo através da carta topográfica e imagem de satélite (Figura 2), utilizando os 
recursos do ArcMap, conforme metodologia descrita por MAGRI \& BAIÃO (2015). Elaborou-se a delimitação das APPs ao longo dos cursos d'água e ao redor das nascentes do córrego do Limão. Os buffers foram criados no menu geoprocessing, ferramenta - BUFFER. Para isso, foi preciso reproduzir essa etapa duas vezes, sendo uma para os cursos d'água, onde delimitou-se uma faixa de 30 metros ao longo de cada margem e a outra para as nascentes, um raio de 50 metros no entorno do ponto central (BRASIL, 2012).

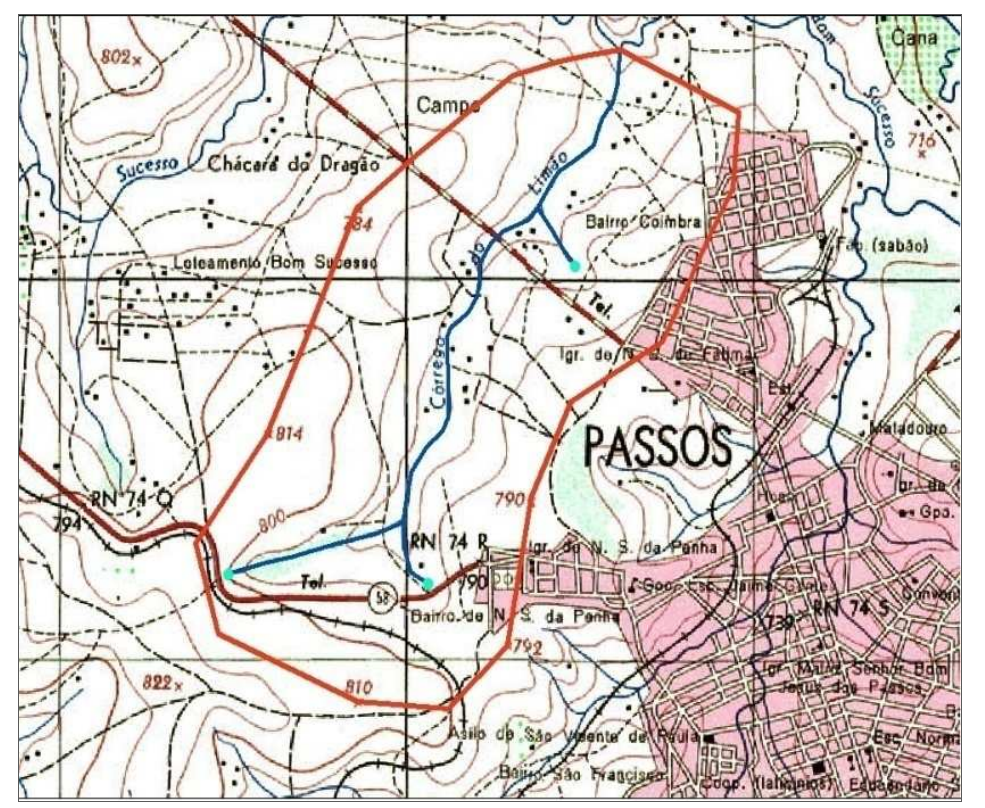

FIGURA 2. Imagem da carta, com hidrografia e delimitação da bacia. Fonte: Adaptado de IBGE (2017)

Para mapeamento do uso e ocupação do solo foram utilizadas imagens de satélite RapidEye com resolução espacial de $5 \mathrm{~m}$, cedidas pelo IBAMA, imagens de satélite obtidas junto ao aplicativo Google Earth e posteriores validações em campo. Com as faixas da bacia e das APPs já determinadas, foram identificados os tipos de cobertura e uso do solo. Assim, foram delimitados os polígonos com homogeneidade quanto ao tipo de uso do solo. As faixas da bacia e das APPs foram classificadas de acordo com a metodologia utilizada por Magri e Baião (2015), em:

- Arbóreo fechado: enquadrou as faixas de florestas muito adensadas de vegetação de grande porte.

- Arbóreo arbustivo aberto: enquadrou as áreas de capoeira com poucas árvores e áreas com maior predominância de gramíneas.

- Herbáceo predominante: enquadrou áreas de campo e área aberta.

- Solo exposto: áreas sem nenhum tipo de cobertura vegetal.

- Áreas consolidadas: enquadrou em áreas ocupação antrópica, como por exemplo, casas, ruas e avenidas.

- Agricultura: enquadrou as áreas usadas para agricultura.

- Loteamento: enquadrou as áreas com subdivisão de glebas em lotes destinados à edificação, com abertura de novas vias de circulação, de logradouros públicos ou prolongamento, modificação ou ampliação das vias e logradouros existentes. 
As visitas a campo foram realizadas para reconhecimento geral da bacia, confirmação dos tipos de uso e ocupação do solo previamente mapeados e levantamento das degradações. Utilizou-se um GPS de navegação da Garmin e efetuou-se o registro fotográfico dos aspectos de interesse.

Para levantamento das degradações, utilizou-se um check-list abrangendo aspectos macroscópicos relativos a intervenções nos recursos hídricos e na mata ciliar, disposição de resíduos sólidos e processos do meio físico, tais como erosão e assoreamento. Esse reconhecimento foi útil para a construção dos mapas teóricos com fatores reais de campo, e para avaliar a degradação das APPs e dos recursos hídricos.

\section{RESULTADOS E DISCUSSÃO}

Compreendendo três nascentes e os seus respectivos cursos d'água, a bacia possui uma área de 589,5 hectares $\left(5,89 \mathrm{~km}^{2}\right)$. Trata-se de uma bacia hidrográfica predominantemente urbanizada. Na Figura 3 é apresentado o mapa de uso e ocupação do solo na bacia hidrográfica.

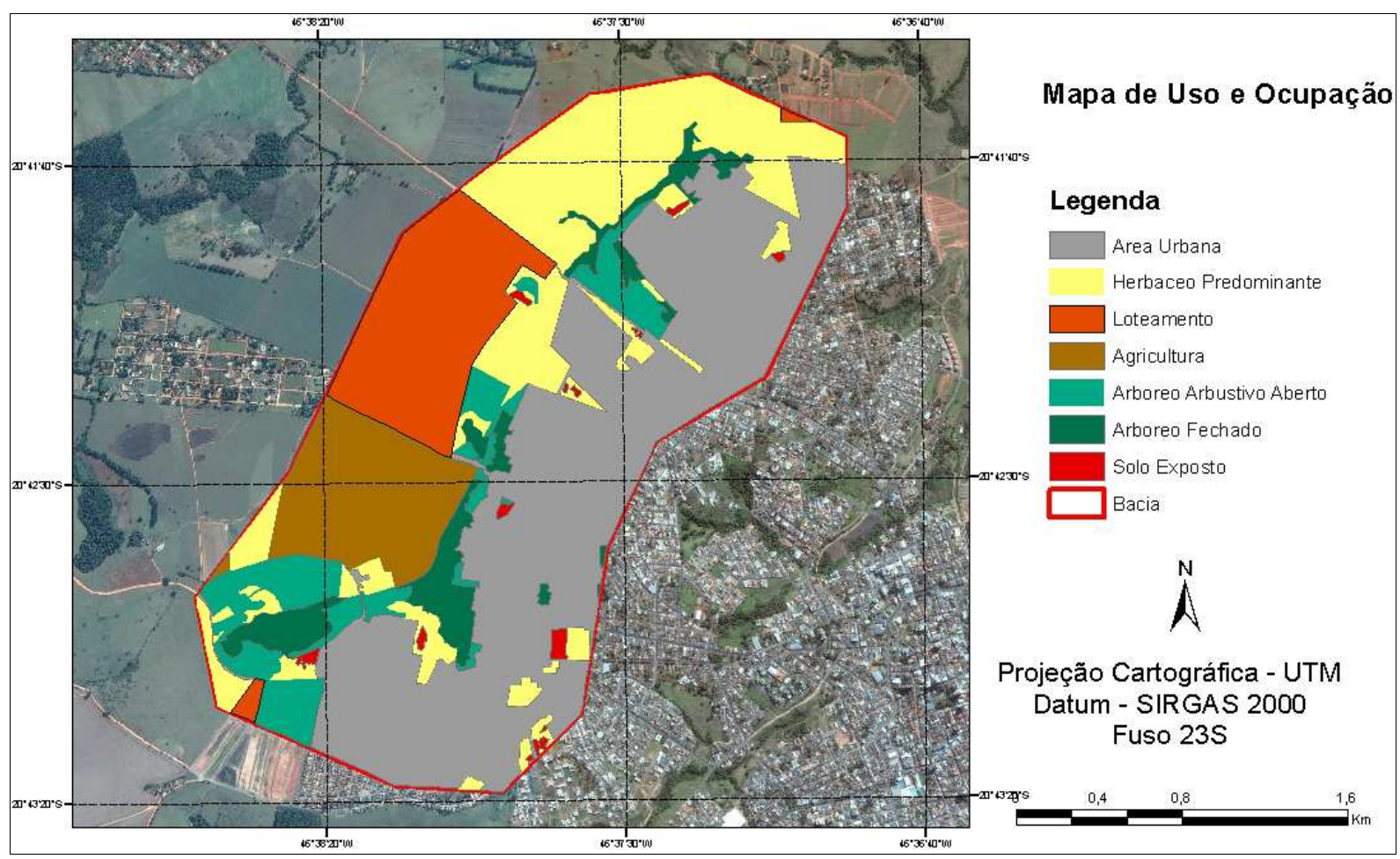

FIGURA 3. Mapa de Uso e Ocupação do Solo da bacia hidrográfica do Córrego do Limão. Fonte: Os Autores

A Tabela 1 mostra os dados quantitativos, onde pode-se observar que na área da bacia predomina o uso e ocupação em Áreas consolidadas, abrangendo uma área de 250,66 ha, com $42,53 \%$, seguido da vegetação herbáceo predominante com 124,85 ha e 21,14\%, Loteamento com 70,07 ha e 11,89\%, Agricultura 55,51 ha e 9,42\%, arbóreo arbustivo aberto com 49,66 ha e $8,43 \%$, Arbóreo Fechado com 34,64 ha e $5,88 \%$, e por último solo exposto com 4,11 ha e $0,70 \%$.

As Áreas de Preservação Permanente de recursos hídricos na bacia hidrográfica compreendem uma área de 28,83 hectares $\left(288.264,10 \mathrm{~m}^{2}\right)$, segundo 0 novo Código Florestal (BRASIL, 2012). A quantificação e categorização da 
degradação da APP foi realizada por meio de imagem de satélite, visitas a campo e pelo programa ArcMap, conforme apresenta o Mapa de Categorias de Degradação (Figura 4).

TABELA 1. Quantificação dos tipos de uso e ocupação existentes na área total da bacia

\begin{tabular}{lrr}
\hline Categorias de degradação & Área (ha) & $\%$ \\
\hline Áreas consolidadas & 250,66 & 42,53 \\
Herbáceo predominante & 124,85 & 21,14 \\
Loteamento & 70,07 & 11,89 \\
Cultura & 55,51 & 9,42 \\
Arbóreo Arbustivo Aberto & 49,66 & 8,43 \\
Arbóreo Fechado & 34,64 & 5,88 \\
Solo Exposto & 4,11 & 0,70 \\
\hline
\end{tabular}

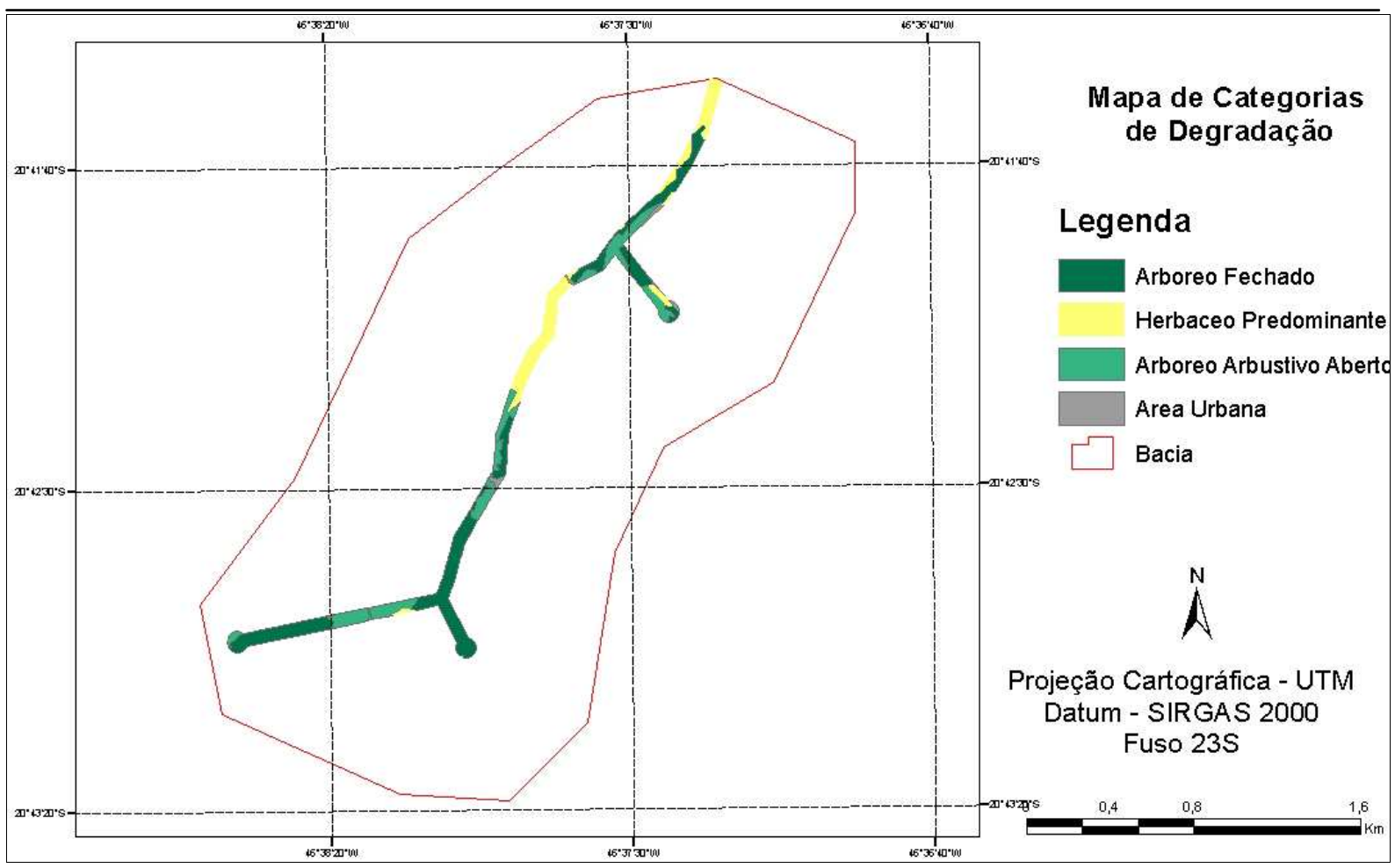

FIGURA 4.Mapa de Categorias de Degradação das APPs

A Tabela 2 mostra os dados quantitativos, onde pode-se observar que na área das APPs predomina a vegetação arbóreo fechado, abrangendo uma área de 13,87ha, que corresponde a $48 \%$ da área total da APP, seguido da vegetação arbóreo arbustivo aberto com $27 \%$ que corresponde a 7,74ha, herbáceo predominante com $23 \%$ correspondendo a 6,72 ha e as áreas consolidadas com $2 \%$ e 0,64ha.

Quanto ao cumprimento da legislação ambiental, principalmente no que se refere à proteção dos cursos d'água com base na Lei Florestal, verifica-se que a bacia hidrográfica do córrego do Limão apresenta uma realidade diferente da que está prevista na legislação, apesar da necessidade de preservação da vegetação natural ao redor das nascentes e ao longo dos rios, existe um desrespeito às normas, já que algumas áreas, não estão de acordo com a metragem estipulada 
pela base legal (GARCIA et al., 2015).

No que se refere ao uso irregular das APPs, há o predomínio de pastagens, com 6,72 hectares, o que representa $23 \%$ do total de conflitos em APPs (Tabela 2). Este uso é prejudicial, pois alguns produtores rurais desrespeitam as leis para que o gado tenha acesso ao rio para sua dessedentação, causando assim degradação tanto na vegetação quanto na água (GARCIA et al., 2015), podendo acarretar na diminuição significativa da qualidade da água, muitas vezes, dificultando e encarecendo o seu tratamento (TSUJII et al., 2015).

TABELA 2.Classificação e quantificação dos tipos de uso e ocupação existentes nas APPs

\begin{tabular}{lcc}
\hline Categorias de degradação & Área (ha) & $\%$ \\
\hline Arbóreo Fechado & 13,87 & 48 \\
Arbóreo Arbustivo Aberto & 7,74 & 27 \\
Herbáceo predominante & 6,72 & 23 \\
Áreas Consolidadas & 0,64 & 2 \\
\hline
\end{tabular}

Alguns fatores que puderam ser identificados na bacia do córrego do Limão durante os levantamentos de campo foram: presença de loteamentos de residências de baixo padrão, ausência de vegetação ciliar, áreas com solo exposto e áreas com disposição irregular de resíduos sólidos e entulhos. Nos tópicos abaixo são apresentados e discutidos os principais aspectos de degradação ambiental encontrados na área.

A Figura 5 mostra informações da bacia do córrego do Limão por imagem do Google Earth. Os números 1, 2 e 3 são as nascentes e os pontos A, B e C são pontos relevantes que são discutidos a seguir.

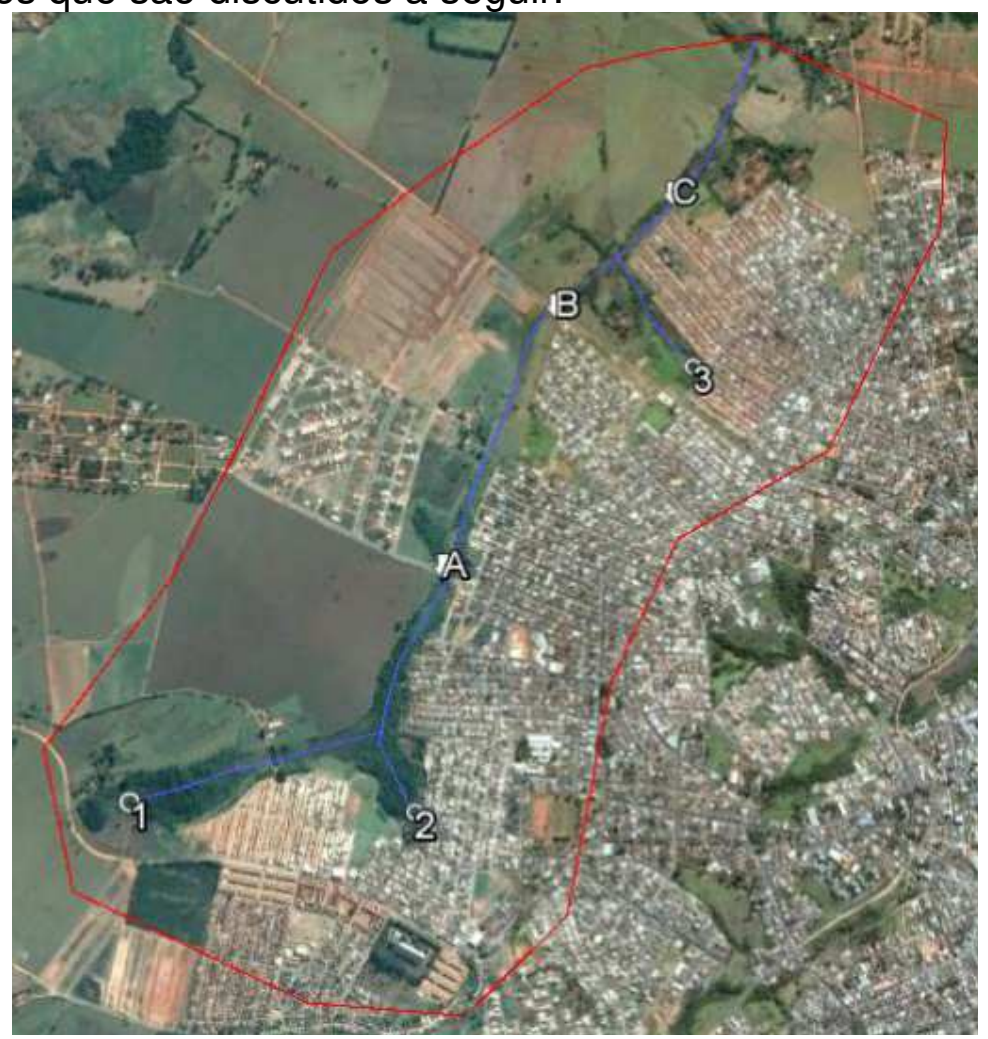

FIGURA 5. Bacia hidrográfica do córrego do Limão e suas nascentes. Fonte: Google Earth Pro

Alguns pontos do curso d'água não se encontram preservados, como mostra ENCICLOPÉDIA BIOSFERA, Centro Científico Conhecer - Goiânia, v.14 n.25; p.84 
na Figura 6, no ponto "A" parte da vegetação foi suprimida por abertura de uma via pavimentada. No Ponto "B" fica evidente (Figura 7) a ausência de vegetação nativa ao redor do curso d'água, e em algumas partes solo totalmente exposto, causando assoreamento dos corpos d'água.

A degradação das matas ciliares contribui para o assoreamento, elevação da turbidez da água e para a erosão das margens dos cursos d'água, transportando substâncias poluidoras, como por exemplo, defensivos e fertilizantes agrícolas (LIMA et al., 2013).

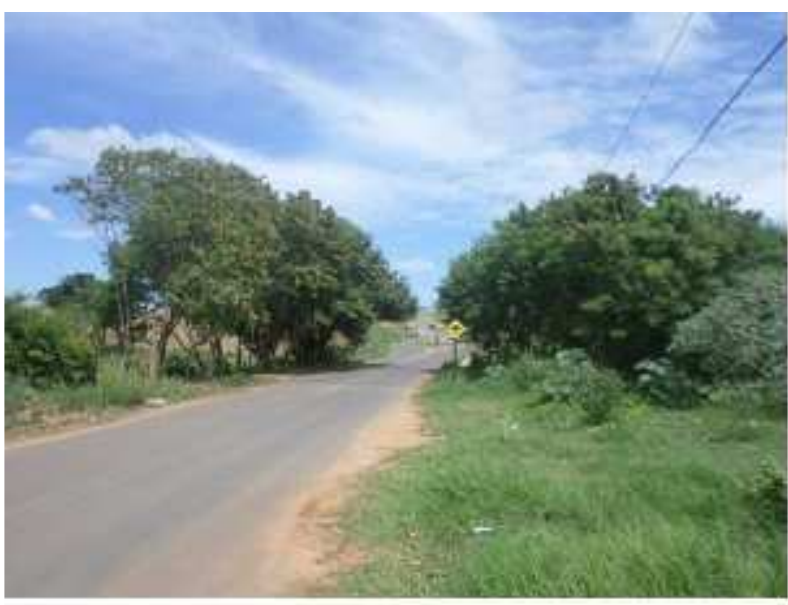

FIGURA 6. Interrupção da vegetação da APP devido a pavimentação de rua

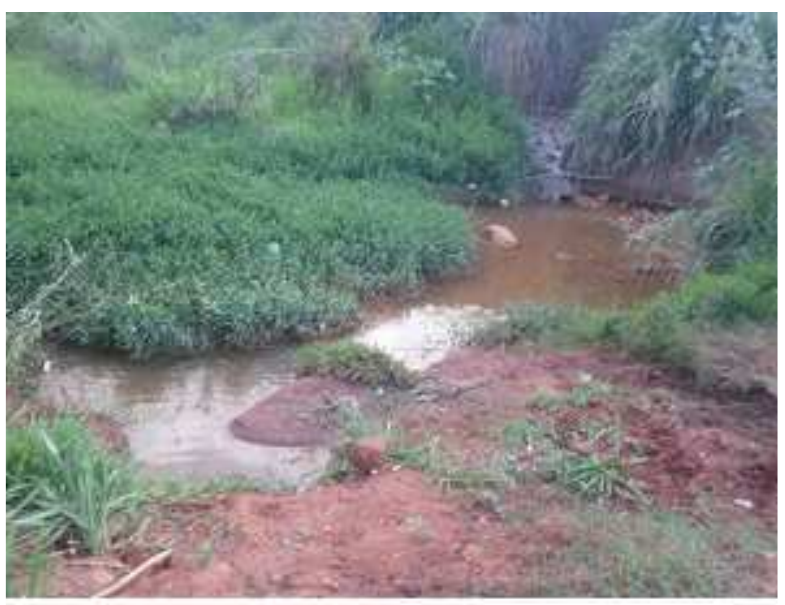

FIGURA 7. Assoreamento no curso d'água e ausência de vegetação nativa

Foi constatado no ponto "C" parte da vegetação com solo exposto em encosta, com processos erosivos incipientes e consequentemente um assoreamento no curso d'água, como mostra a Figura 8. Na Figura 9 pode-se perceber 0 lançamento de resíduos como pneu, madeiras e partes de objetos, direto no curso d'água. Também é possível verificar alguns pontos sem vegetação ao redor do curso d'água o que pode causar o assoreamento.
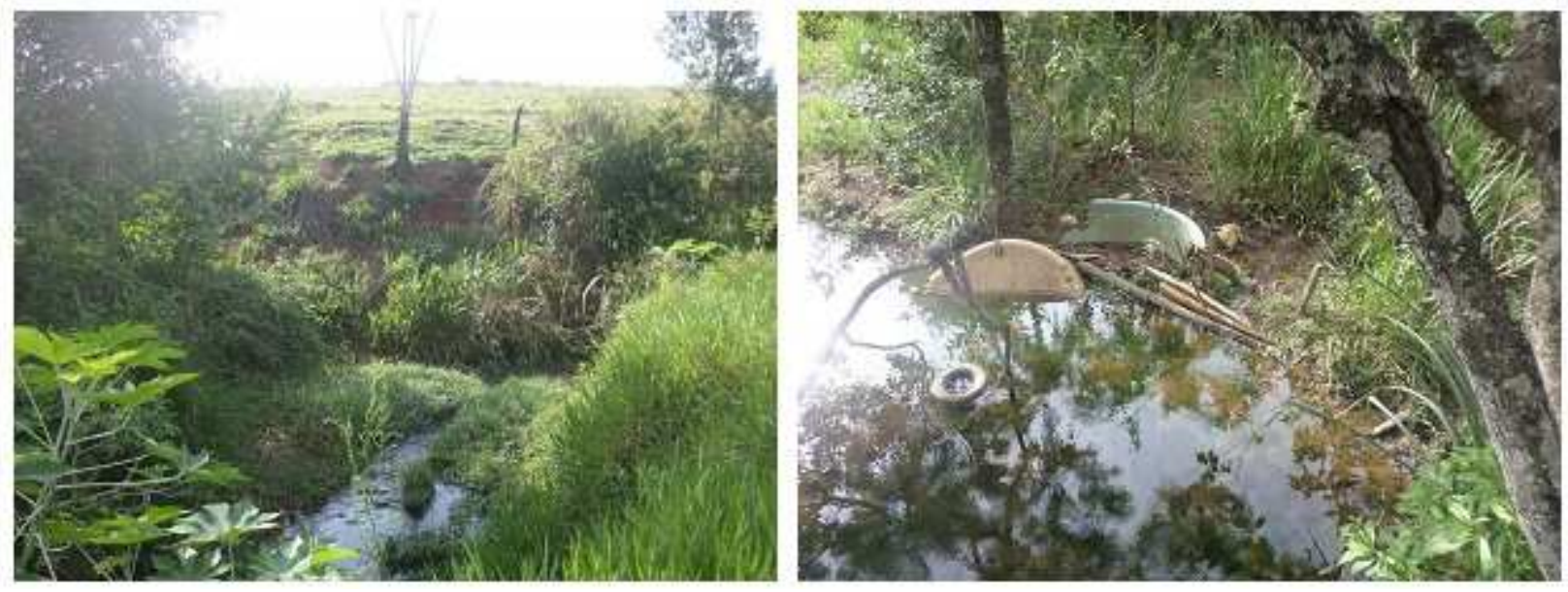

FIGURA 3. Parte da vegetação com solo exposto

FIGURA 4. Resíduos lançados no curso d'água 


\section{Nascente 1}

Na Figura 10 nota-se parte da APP da nascente 1 do córrego do Limão, com vegetação arbórea fechada, gramíneas e solo exposto, que não pode ser visto na imagem de satélite. Pode-se observar o desmatamento de parte da APP da nascente, com uso antrópico e solo exposto, verifica-se também a construção de uma residência e um barracão localizado nas proximidades da APP da nascente (Figura 11).

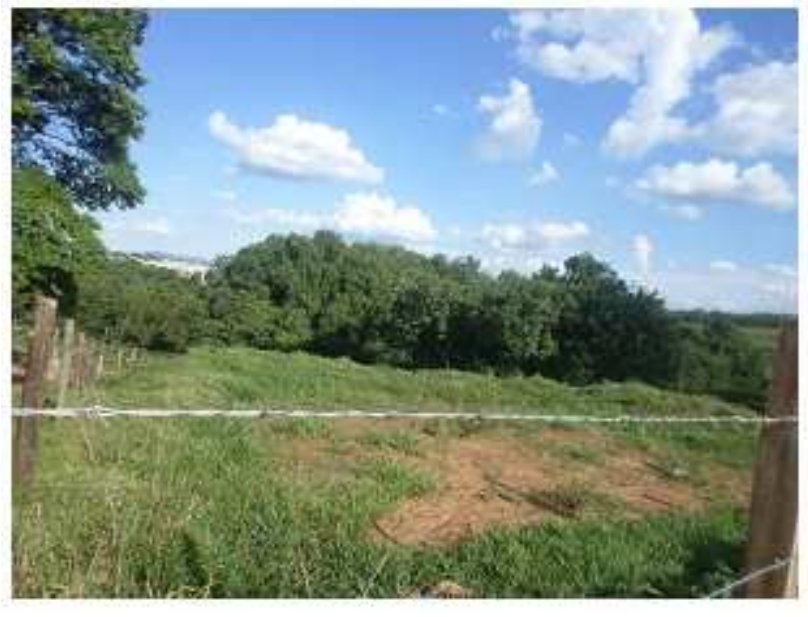

FIGURA 10. Vista geral da Nascente 1 com vegetação arbórea fechada

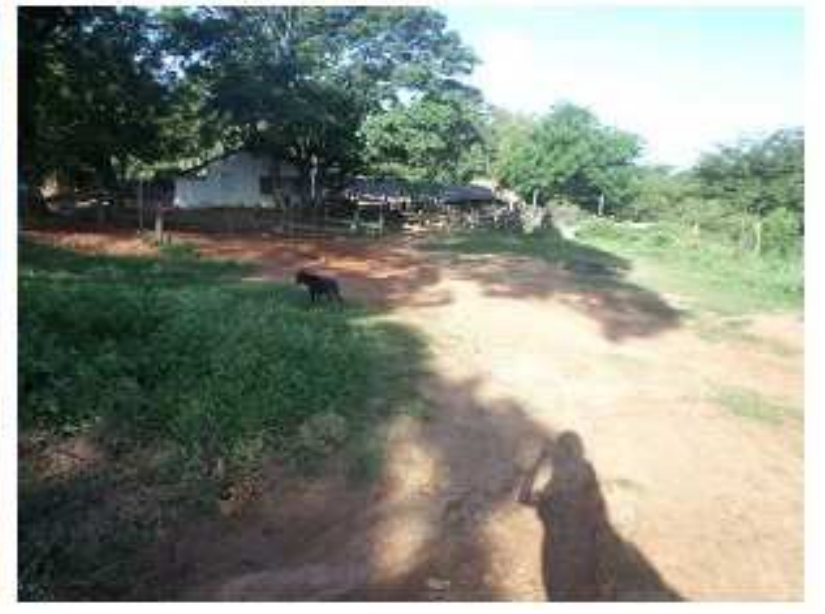

11. Propriedade rural construída a poucos metros dentro da APP da nascente

\section{Nascente 2}

$\mathrm{Na}$ figura 12 observa-se parte da vegetação dentro da APP da nascente 2 e área com solo exposto. A mesma foi desmatada pelos moradores do local. Foi constatado o lançamento de água pluvial na nascente com suspeita de lançamento de efluentes (Figura 13). Moradores próximos ao local descreveram ser lançamento de esgoto, e no local há indícios de poluição, com bastante disposição irregular de resíduos sólidos.

A emissão de efluentes e a deposição de resíduos sólidos em locais indevidos, como nas nascentes são indícios de falta de saneamento básico e situação precária. A falta desse serviço acarreta problemas pontuais e difusos, como a poluição e contaminação das águas, a disseminação de doenças, como hepatite, diarréia, o que reflete diretamente no nível de saúde da população acarretando em mais consequências socioeconômicas e desequilíbrio ambiental (WSP, 2009).

Foi observada existência de uma construção residencial a poucos metros da nascente, situada em sua APP, causando assim grandes impactos ambientais negativos sobre a nascente. A vegetação foi desmatada deixando o solo exposto, muita poluição é gerada com o lançamento de resíduos sólidos e entulhos no solo e na nascente (Figuras 14 e 15), podendo causar problemas sanitários (SILVA NETO et al., 2013).

Foi possível observar, conforme mostra as Figuras 16 e 17 que foi construído 
um pequeno poço pelo morador do local para armazenamento da água com objetivo de irrigar sua plantação (subsistência).

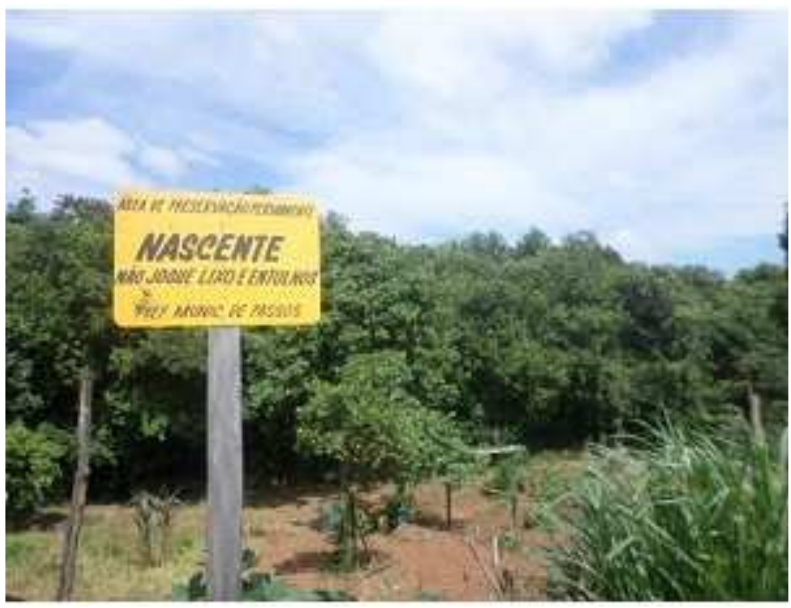

FIGURA 12. Vista geral da Nascente 2 do córrego do Limão

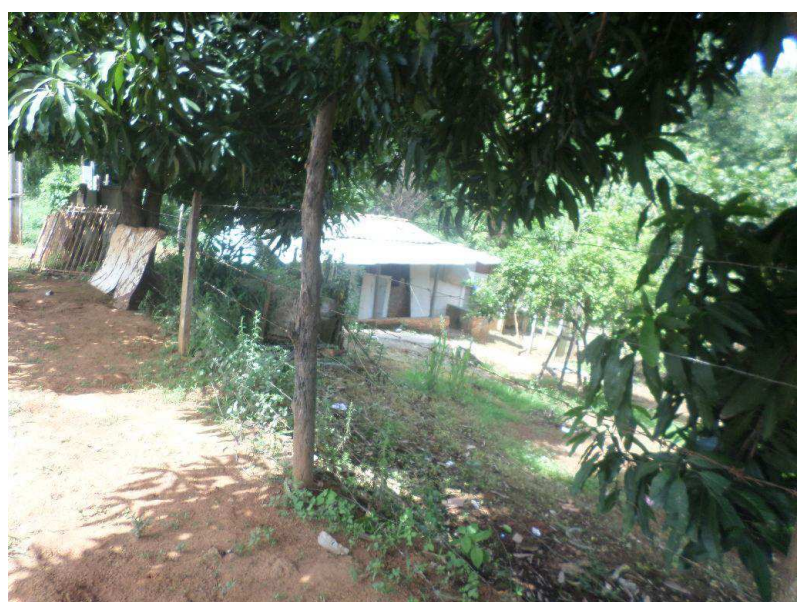

FIGURA 14. Ocupação irregular localizada dentro da APP, a poucos metros da nascente

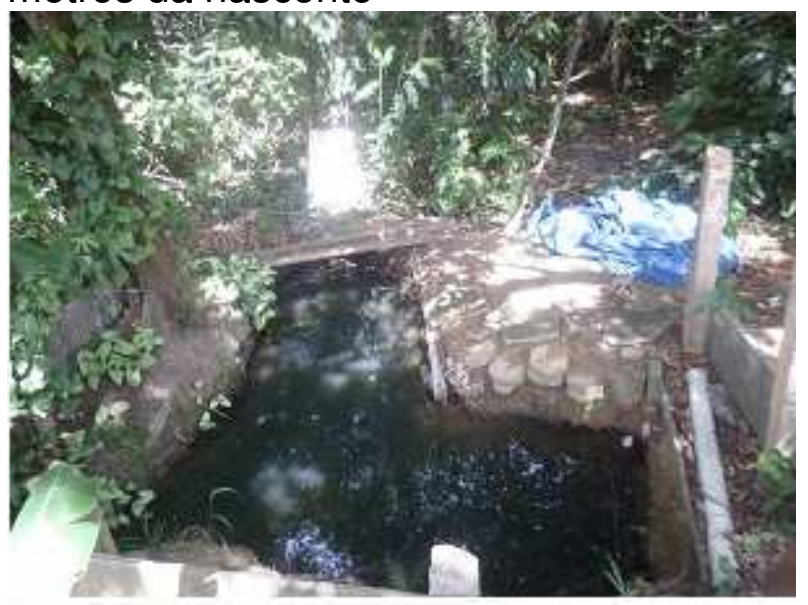

FIGURA 16. Poço construído para irrigar a plantação do morador no local

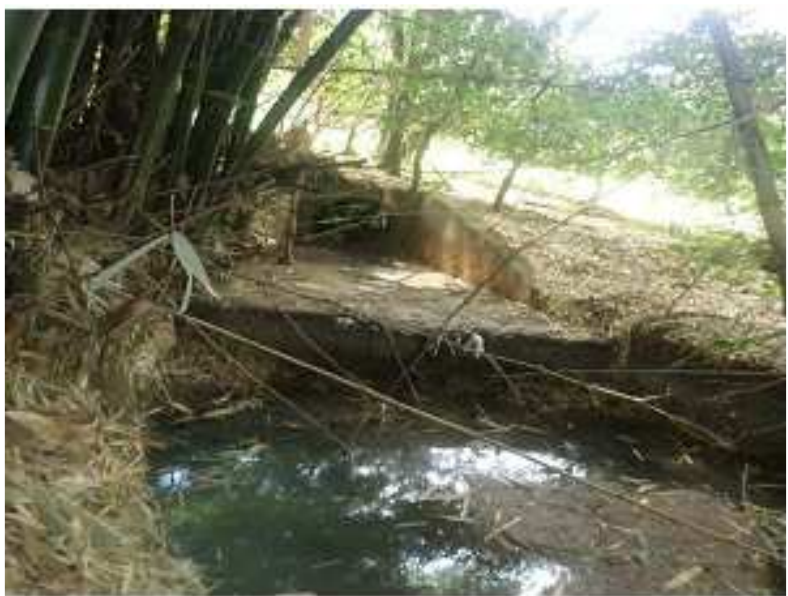

FIGURA 13. Lançamento de água pluvial na nascente, com suspeita de lançamento de efluentes

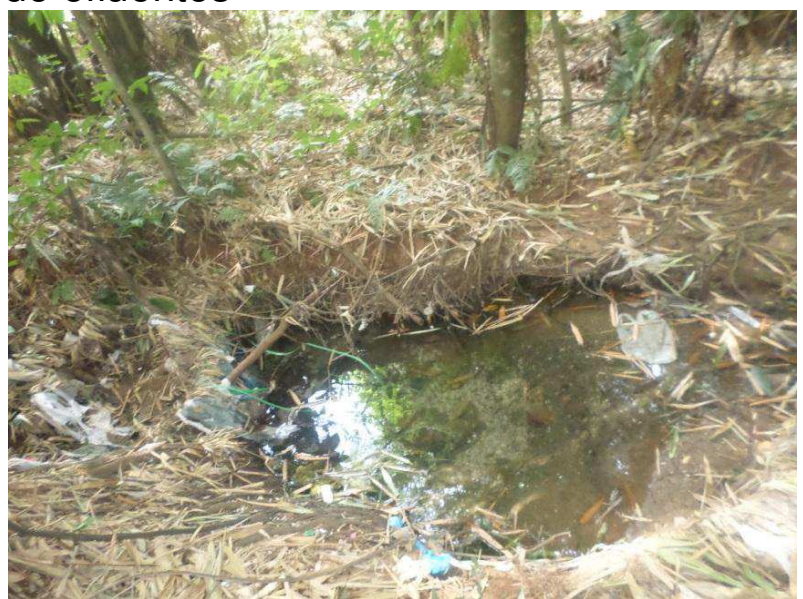

FIGURA 15. Presença de resíduos no curso d'água e na APP da nascente do córrego do Limão

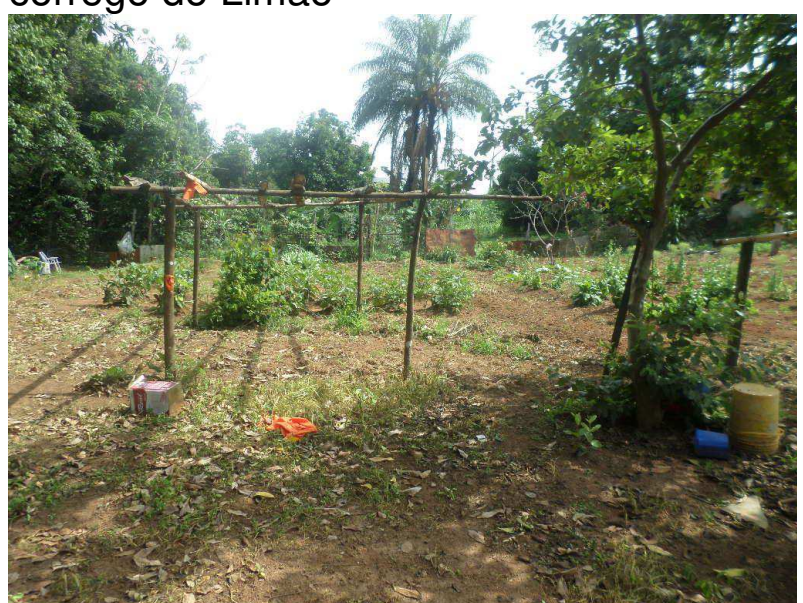

FIGURA 17. Plantação dentro da APP da nascente do córrego 


\section{Nascente 3}

$\mathrm{Na}$ nascente 3 (Figura 18) localizada no bairro Nova Califórnia, pode-se observar problemas similares aos das outras nascentes citadas anteriormente. Como ocupação irregular, lançamentos de resíduos sólidos e desmatamento da vegetação nativa da APP.

Como a bacia está localizada em área urbana, na Figura 19 é possível notar uma rua bem perto na nascente e algumas habitações que seriam irregulares devido ao fato de estarem situadas na faixa da APP. Verifica-se também alguns impactos que são causados pelos moradores próximos da APP, como o lançamento de resíduos e entulhos na APP da nascente. Esses resíduos podem migrar para outras áreas através da precipitação e escoamento da chuva, podendo ser despejados no curso d'água.

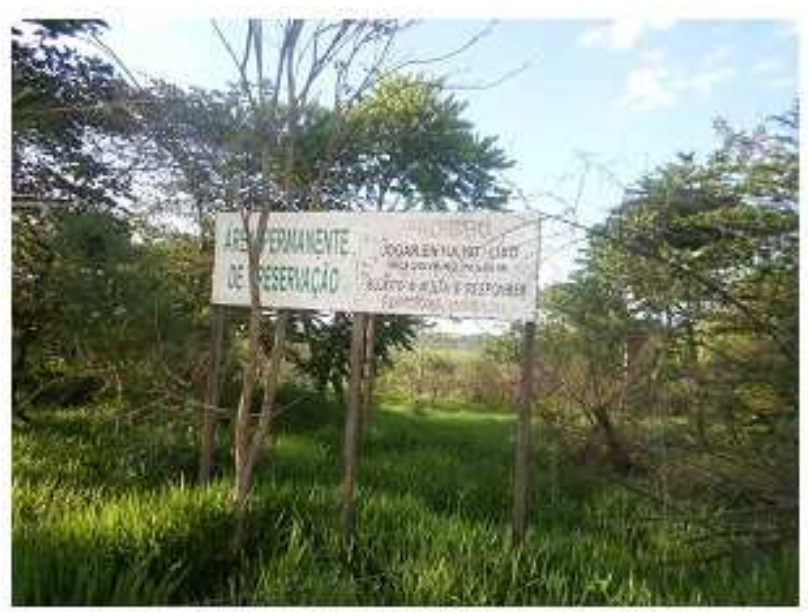

FIGURA 18. Nascente 3 do córrego do Limão

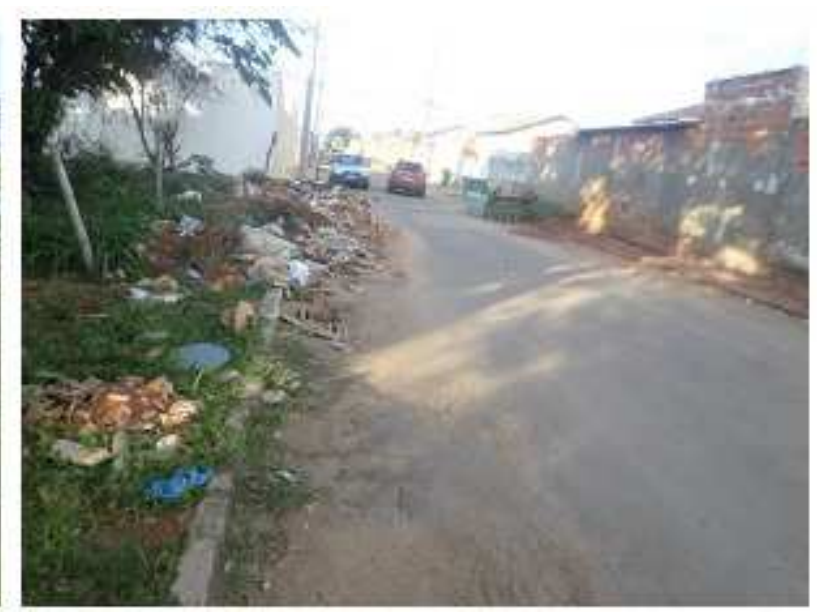

FIGURA 19. Disposição de entulhos e ocupação irregular a poucos metros da APP da nascente 3

\section{Propostas para Minimização da Degradação Ambiental}

As principais degradações ambientais encontradas referem-se aos conflitos de uso (áreas construídas em APP), ausência de vegetação nativa em APP, lançamentos de esgoto nos cursos d'água e disposição irregular de resíduos sólidos. As intervenções em APP impedem/inibem recuperação natural da vegetação, ocasionando um impacto negativo em toda biota, caracterizado pela redução da disponibilidade de alimento, abrigo e corredores de dispersão para a fauna.

De acordo com MORI et al. (2015), a vegetação ciliar tem como função realizar o filtro de retenção sedimentos e nutrientes que chegam ao corpo hídrico, diminui consideravelmente os processos erosivos nas margens de recursos hídricos, mantém o equilíbrio térmico das águas e fornece material orgânico que serve alimento à fauna aquática, além da presença de pequenos galhos na água serem essenciais para o ciclo de nutrientes e servir como abrigo da fauna aquática, a exemplo dos invertebrados bentônicos.

GONÇALVES (2016) aponta que a recuperação das formações ciliares pode ser o simples isolamento da área e a retirada dos fatores de degradação, o local deverá ser cercado para evitar a entrada de pessoas e animais dando início aos 
processos de recuperação das características físicas dos solos.

O maior obstáculo identificado para a recuperação das APPs da bacia do córrego do Limão foram as habitações que se encontram irregulares dentro das APPs que preservam o córrego. $O$ ideal seria que a população que está localizada irregularmente dentro das APPs fosse transferida para outro local, preferencialmente para locais próximos de onde viviam com o intuito de que não se tenha mudanças drásticas no costume de vida das pessoas.

Quanto à suspeita de lançamento de esgoto no curso d'água, onde não é comprovado o lançamento direto de efluentes líquidos, é sugerido que sejam realizadas análises de água para afirmar ou não sobre a dúvida de poluição. Se for confirmada à presença de esgotos, é necessário extinguir o contato dos corpos de água com os agentes poluentes, a partir da construção de interceptores, além de melhorar o monitoramento da rede de esgoto paralela ao curso d'água (CARDOSO, 2009).

O lançamento inadequado de resíduos sólidos é um problema muito evidente na bacia em questão. Podem-se observar vários pontos dentro da bacia onde são acumulados pilhas de resíduos sólidos, entulhos de construção, etc. Inclusive há esses depósitos dentro das APPs e até no curso d'água.

Assim sendo, é de fundamental importância para a restauração da bacia que sejam retirados os resíduos sólidos presentes. A limpeza deve ser feita pela prefeitura e recomenda-se também fazer uma fiscalização e identificação dos autores e responsáveis destes resíduos (MONTES \& LEITE, 2008).

Outro motivo de ocorrência dos problemas ambientais na bacia é devido a ineficiência de educação ambiental e falta de conscientização da população. Com isso a população vem desmatando as matas ciliares e também outras vegetações que serviam como proteção do solo, deixando-o totalmente exposto nas margens do córrego, aumentando os processos erosivos. A população também faz o lançamento inadequado do lixo em lugares como no solo e no curso d'água, entre outros, pois não se tem a conscientização ambiental sobre a importância de preservar a natureza.

Desta forma, para que a recuperação da bacia ocorra de forma eficaz é indispensável que seja implantado um programa de educação ambiental voltado para a população. O intuito dessa educação ambiental é impedir que os processos de restauração não sejam conservados, assim como também impossibilitara a recorrência dos agravos já presentes na bacia (SILVA NETO et al., 2013).

O programa pode ser desenvolvido juntamente com a programação das escolas para as crianças e adolescentes através de palestras, abordando assuntos como, por exemplo: disposição adequada de resíduos sólidos, a importância da mata ciliar para manter o equilíbrio do curso d'água, entre outros.

\section{CONCLUSÃO}

Existem conflitos de uso e ocupação dos solos na bacia hidrográfica do Córrego do Limão. As pastagens e edificações ocupam, juntas e indevidamente, $25 \%$ do total das áreas de preservação permanente, enquanto que $48 \%$ é coberta por vegetação arbórea.

As principais causas de degradações das matas ciliares e recursos hídricos da bacia são a disposição irregular de resíduos sólidos, desmatamento, erosão, assoreamento, além dos usos conflitantes.

As áreas indicadas a serem reflorestadas são aquelas classificadas como 
herbáceo predominante e arbóreo arbustivo aberto. A quantidade de área a ser reflorestada corresponde a $50 \%$ da área total de APPs, que compreende uma área total de $288.264,10$ metros quadrados.

As técnicas de geoprocessamento são essenciais para a obtenção dos mapas do uso do solo e da degradação das APPs, auxiliando de base para o cumprimento do código florestal, principalmente no que se refere às áreas de APPs e para futuros planejamentos do município.

\section{AGRADECIMENTOS}

Agradecemos à Universidade do Estado de Minas Gerais - Unidade Passos pela infraestrutura concedida para a realização deste trabalho.

\section{REFERÊNCIAS}

ANDRADE, H.; FONSECA, L. D. Pedologia. In: COLLARES, E. G. (Org.). Zoneamento Ambiental das sub-bacias hidrográficas dos afluentes mineiros do Médio Rio Grande: aspectos dos meios físico e biótico. 1ed.Passos: EdiFesp, v. 3, p. 167-183.2013.

BRASIL. Lei no 12.651 de 25 de maio de 2012. Dispõe sobre a proteção da vegetação nativa; altera as Leis no 6.938, de 31 de agosto de 1981, 9.393, de 19 de dezembro de 1996, e 11.428, de 22 de dezembro de 2006; revoga as Leis № 4.771, de 15 de setembro de 1965, e 7.754, de 14 de abril de 1989, e a Medida Provisória no 2.166-67, de 24 de agosto de 2001; e dá outras providências. Diário Oficial da União, Brasília, DF, 28 maio 2012. Disponível em: < http://www.planalto.gov.br/ccivil_03/_Ato2011- 2014/2012/Lei/L12651.htm>. Acesso em 01 de abr. 2017.

CARDOSO, F. J. Análise, concepção e intervenções nos fundos de vale da cidade de Alfenas [MG]. Labor \& Engenho, Campinas [SP], Brasil, v.3, n.1, p.1-20, 2009. Disponível em:< http://periodicos.sbu.unicamp.br/ojs/index.php/labore/article/view/1736/1962>. Acesso em 01 de abr. 2017.

COLLARES, E. G. Zoneamento Ambiental das Sub-bacias Hidrográficas dos Afluentes Mineiros do Médio Rio Grande: Aspectos dos Meios Físico e Biótico. 1. ed. Passos - MG: Edifesp, 2013. v. 4. 269p.

GARCIA, Y. M.; CAMPOS, S.; SPADOTTO, A. J.; CAMPOS, M.; SILVEIRA, G. R. P. Caracterização de conflitos de uso do solo em APPs na bacia hidrográfica do córrego Barra Seca (Pederneiras/SP). Energia na Agricultura (UNESP. Botucatú. CD-Rom), v. 30, p. 68, 2015. Disponível em: < http://dx.doi.org/10.17224/EnergAgric.2015v30n1p68-73>

GONÇALVES, D. S., SOUZA, P. A., OLIVEIRA, A. L., MARTINS, T. S. Diagnóstico Ambiental E Proposta De Plano De Recuperação Da App, Fazenda Santa Juliana, Cariri Do Tocantins-To. Nucleus, v. 13, n. 1, p. 261-276, 2016. Disponível em: < http://www.nucleus.feituverava.com.br/index.php/nucleus/article/view/1562/1983> Acesso em 01 de fev. 2017

IBGE. Instituto Brasileiro de Geografia e Estatística. Disponível ENCICLOPÉDIA BIOSFERA, Centro Científico Conhecer - Goiânia, v.14 n.25; p.90 2017 
em:<http://www.ibge.gov.br/>. Acesso em: 10 jan. 2017.

JACOB, S. M. Análise do uso e ocupação das APPs da bacia do córrego do Mineirinho e propostas para recuperação das duas nascentes. Trabalho de Conclusão de Curso. Escola de Engenharia de São Carlos, Universidade de São Paulo. São Carlos, 2010. Disponível em: $<$ http://www.tcc.sc.usp.br/tce/disponiveis/18/180300/tce-14022011151251/?\&lang=br> Acesso em: 01 set. 2016

LIMA, A. B.; CHAVES, H. M. L. Avaliação da integridade ripária da bacia do Rib. Pipiripau utilizando o SVAP. In: XX Simpósio Brasileiro de Recursos Hídricos, 2013, Bento Gonçalves. Anais do X Simpósio Brasileiro de Recursos Hídricos, 2013. v. 1.

LIMA, W. P.; FERRAZ, S. F. B.; FERRAZ, K. M. P. M. B. Interações bióticas e abióticas na paisagem: uma perspectiva eco-hidrológica. In: CALIJURI, M. C.; CUNHA, D. G. F. (Orgs.) Engenharia Ambiental: conceitos, tecnologias e gestão. Rio de Janeiro: Elsevier, 2013.

MAGRI, R. A F.; BAIÃO, T. C. Restoration of degraded APPs and the viability of carbon sequestration: study of an urban watershed in the city of Passos - MG. Ambiência (UNICENTRO), v. 12, p. 921-930, 2016. Disponível em: <http://dx.doi.org/10.5935/ambiencia.2016.Especial.17> 10.5935/ambiencia.2016.Especial.17

MAGRI, R. A. F.; PEJON, O. J. ; COLLARES, E. G. Caracterização do relevo. In: COLLARES, E. G. (Org.). Zoneamento Ambiental das sub-bacias hidrográficas dos afluentes mineiros do Médio Rio Grande: aspectos dos meios físico e biótico. 1ed.Passos: EdiFesp, v. 3, p. 114-149, 2013.

MONTES, R. M.; LEITE, J. F. A Drenagem Urbana de Águas Pluviais e seus Impactos Cenário Atual da Bacia do Córrego Vaca Brava-GoiâniaGO. Goiânia/GO: Universidade Católica de Goiás, 2008.

MORI, G. B.; PAULA, F. R.; FERRAZ, S. F. B.; CAMARGO, A. F. M.; MARTINELLI, L. A. Influence of landscape properties on stream water quality in agricultural catchments in Southeastern Brazil. Annales de Limnologie - International Journal of Limnology, v. 51, p. 11-21, 2015. Disponível em: <http://dx.doi.org/10.1051/limn/2014029> DOI: 10.1051/limn/2014029

SILVA NETO, C. M.; OKANO, S. F.; CARNEIRO, V. A.; GONÇALVES, B. B. Ocupação de áreas de preservação permanentes dos canais fluviais em ambiente urbano do município de Jataí - GO. Revista Percurso, v. 5, n. 2, p.73-89, 2013.

TSUJII, P. K.; RIBEIRO, A. C. C.; CARNEIRO, V. A.; CARNEIRO, V. A.; SILVA NETO, C. M.; GONÇALVES, B. B. Uso e Ocupação das Áreas de Preservação Permanentes no Sudoeste Goiano. Revista de Geografia (UFPE), v. 31, n. 3, 2014

WATER AND SANITATION PROGRAM - WSP. Economic impacts of Sanitation in Lao PDR: a five-country study conducted in Cambodia, Indonesia, Lao PDR, the Philippines, and Vietnam under the Economics of Sanitation Initiative (ESI). Jakarta: The World Bank, 2009. 